Inhibition of poly(A) polymerase by rifamycin derivatives

Samson T. Jacob and Kathleen M. Rose

Department of Pharmacology, Milton S.Hershey Medical Center, Pennsylvania State University College of Medicine, Hershey, Pennsylvania 17033, USA

Received 11 September 1974

ABSTRACT

The effect of several rifamycin derivatives on poly(A) synthesis in vitro was tested using purified rat liver mitochondrial poly(A) polymerase assayed with an exogenous primer. When used at a concentration of $300 \mu \mathrm{g} /$ $\mathrm{ml}$, derivatives AF/013, PR/19, AF/AETP, M/88 and AF/ABDP completely inhibited activity corresponding to $50 \mu \mathrm{g}$ of enzyme protein. Under similar conditions, derivatives DMAO and AF/MO failed to inhibit enzyme activity. Studies with PR/19 showed that the drug interacted directly with the enzyme molecule and did not affect the enzyme-primer complex formation. The inhibition by the drug could be reversed by increasing the substrate (ATP) concentration. It is concluded that some rifamycin derivatives can specifically inhibit template-independent nucleotide chain elongation reactions.

\title{
INTRODUCTION
}

Rifampicin is probably the best known chemical derivative of rifamycin, the antibiotic produced by Streptomyces Mediterranei. It has been widely used as an important tool in studying bacterial transcription and to a limited extent as a chemotherapeutic agent. This drug inhibits bacterial RNA synthesis by binding to the RNA polymerase molecule $e^{1,2}$. Studies on the mechanism of this inhibition have revealed that the drug blocks the initiation of RNA synthesis ${ }^{3-5}$.

Rifampicin itself does not inhibit mammalian nuclear RNA polymerases $^{1,6-9}$, but the availability of a variety of semisynthetic derivatives of rifamycin has prompted several investigators to test their effects on mammalian RNA polymerases. Such studies have revealed that both nucleolar and nucleoplasmic RNA polymerases of calf thymus ${ }^{9}$, and rat liver $^{8}$ are inhibited by some of these compounds, the most potent derivatives being 4N-benzy1-2,6-dimethyl-piperazinoiminomethyl rifamycin SV (AF/ABDP), the on-octyl oxime of 3-formyl-rifamycin SV (AF/013) and closely related compounds. As expected, these compounds inhibit chain initiation rather than the subsequent elongation or polymerization steps. However, at concentrations that give maximal inhibition of RNA synthesis these compounds can also 
Inhibit the elongation reaction ${ }^{10}$. DNA dependent RNA polymerase catalyzes RNA synthesis in two distinct stages, namely initiation at a specific site on the template with a purine nucleotide, and elongation of the nucleotide chain with other nucleotides. A polymerization reaction independent of a specific initiation step would be an ideal system to study the effect of an agent on the chain elongation reaction specifically. One such reaction is the primer-dependent synthesis of poly(A) catalyzed by poly(A) polymerase.

We solubilized ${ }^{11}$ and partially purified ${ }^{12}$ a poly(A) polymerase from the mitochondria of rat liver. The partially purified enzyme required either an endogenous primer or an exogenous primer such as synthetic poly(A). In this report, several semisynthetic derivatives were tested for their ability to inhibit the primer-dependent poly(A) polymerase activity of rat liver mitochondria. The results suggest that some rifamycin derivatives inhibit poly(A) polymerase-catalyzed synthesis of poly(A) which is essentially a template-independent nucleotide chain elongation reaction. MATERIALS AND METHODS

Isolation and purification of mitochondria. Mitochondria were isolated from rat liver as described previously ${ }^{11}$. In some experiments, mitochondria were further purified by treatment with digitonin ${ }^{13-15}$ which removes any contaminating lysosomes and cytoplasmic ribosomes without destroying the mitochondrial integrity.

Enzyme solubilization and partial purification. Poly(A) polymerase was solubilized from the isolated mitochondria as described by Jacob and Schindler ${ }^{11}$. Mitochondria were suspended $(0.3 \mathrm{ml} / \mathrm{gm}$ original tissue) in $50 \mathrm{mM} \mathrm{Tris}-\mathrm{HCl}$ buffer ( $\mathrm{pH}$ 9.0) containing $20 \%$ glycerol (v/v), $5 \mathrm{mM} \mathrm{MgCl}_{2}$, $50 \mathrm{mM} \mathrm{KCl}$ and $0.1 \mathrm{mM}$ each of EDTA and dithiothreitol. The mitochondrial suspension was sonicated for $45 \mathrm{sec}$. ( $3 \times 15 \mathrm{sec}$ ), incubated for $30 \mathrm{~min}$ at $37^{\circ} \mathrm{C}$ and centrifuged at $105,000 \times \mathrm{g}$ for $1 \mathrm{hr}$.

The high speed supernatant containing the enzyme activity was dialyzed against several volumes of $50 \mathrm{mM}$ potassium phosphate buffer ( $\mathrm{pH}$ 6.8) containing $20 \%$ glycerol $(\mathrm{v} / \mathrm{v}), 5 \mathrm{mM} \mathrm{MgCl}_{2}, 50 \mathrm{mM} \mathrm{KCl}$ and $0.1 \mathrm{mM}$ each of EDTA and dithiothreitol. The dialyzed preparation was then subjected to phosphocellulose chromatography ${ }^{12}$. A sample containing $75 \mathrm{mg}$ of enzyme protein was applied to a $1.5 \times 10 \mathrm{~cm}$ column of phosphocellulose previously equilibrated with $50 \mathrm{mM}$ potassium phosphate buffer (pH 6.8) and the column was washed with at least $20 \mathrm{ml}$ of the same buffer. The column was eluted 
with a linear gradient $(0.05-0.5 \mathrm{M})$ of $\mathrm{KCl}$ in the phosphate buffer. The enzyme was eluted at $0.25 \mathrm{M} \mathrm{KCl}$. The peak fractions were pooled and used for the present studies. In some experiments, the enzyme was further purified by DEAE-Sephadex (A-25) chromatography ${ }^{12}$. Purified enzyme added at least 30 adenylic acid units to the endogenous primer and was therefore a polymerization reaction rather than the terminal addition of only one nucleotide.

Preparation of the primer. Phosphocellulose chromatography of the enzyme resulted in the dissociation of an endogenous primer ${ }^{12}$. The primer was eluted in the $0.05 \mathrm{M} \mathrm{KCl}$ wash fractions. The fractions containing the maximal priming activity were pooled and heated at $100^{\circ} \mathrm{C}$ for $2 \mathrm{~min}$. The heat-coagulated proteins were removed by centrifugation and the supernatant was fractionated on a linear sucrose density gradient ${ }^{12}$. The primer was sedimented at $<4 \mathrm{~S}$. The enzyme after DEAE-Sephadex chromatography utilized commercial poly(A) of average molecular weight 100,000 (Miles Laboratories) more efficiently as a primer than the endogenous (native) primer.

Poly(A) polymerase assay. The enzyme was assayed as described previous $1 y^{11,16}$, using $100-150 \mu \mathrm{g} / \mathrm{ml}$ of enzyme protein and $1.0-1.5 \mathrm{~A}_{260}$ units/ml of the endogenous primer or 6-7 $A_{260}$ units/ml of poly(A). RESULTS

Effect of rifamycin derivatives on the partially purified mitochondrial poly(A) polymerase. The structural formula of the parent rifamycin nucleus is given in Figure 1. The structural formulae and chemical names of the derivatives used in these studies are given in Table 1. Table 2 shows the percent inhibition of partially purified rat liver mitochondrial poly(A) polymerase by some rifamycin derivatives. At a concentration of $300 \dot{\mu g} / \mathrm{ml}, \mathrm{AF} / 013, \mathrm{PR} / 19, \mathrm{AF} / \mathrm{AETP}, \mathrm{M} / 88$ and AF/ABDP (Chemical names given in Table 2) completely inhibited enzyme activity corresponding to $50 \mu \mathrm{g}$ of enzyme protein. It should be noted that a reduction in the amount of enzyme protein used for assay resulted in a proportional decrease in the concentration of the drugs required to achieve complete inhibition. Larger amounts of enzyme were routinely used in order to produce maximal radioactivity incorporated into the product. DMAO and AF/MO failed to inhibit the enzyme activity even when used at concentrations of $600 \mu \mathrm{g} / \mathrm{ml}$. 


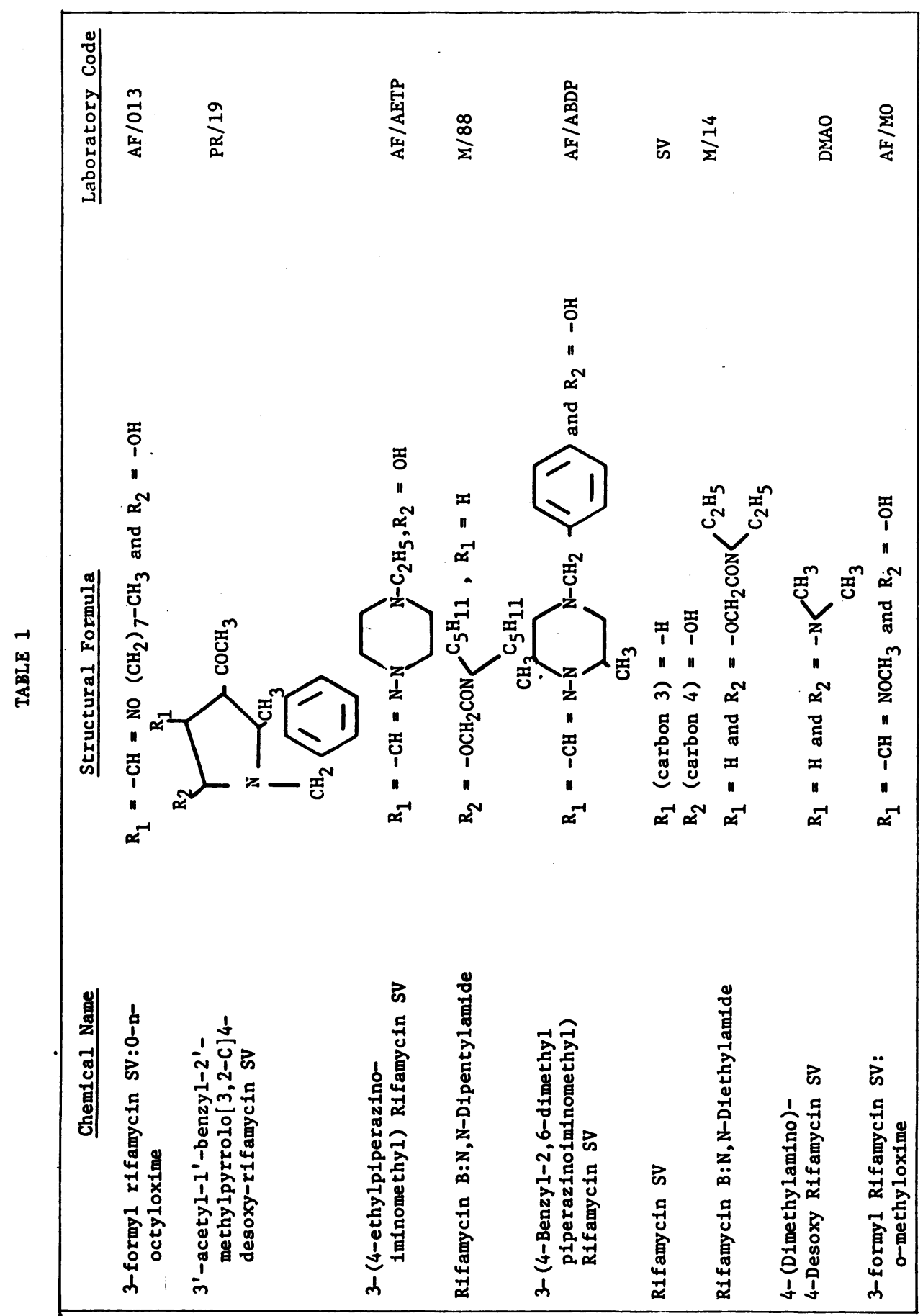


TABLE 2 Effect of rifamycin derivatives on the purified mitochondrial poly(A) polymerase activity.

\begin{tabular}{|cc|}
\hline Derivative (Laboratory Code) & Percent \\
\hline AF/013 & $100(100)$ \\
PR/19 & $100(100)$ \\
AF/AETP & 100 \\
M/88 & 100 \\
AF/ABDP & $100(100)$ \\
Rifamycin SV & 80 \\
M/14 & 40 \\
DMAO & 10 \\
AF/MO & 0 \\
\hline
\end{tabular}

The drugs were dissolved in dimethylformamide (DMF) at a concentration of $10 \mathrm{mg} / \mathrm{ml}$ and $10 \mu 1(100 \mu \mathrm{g})$ were used in each assay. Control samples contained $10 \mu 1$ of DMF which itself had no inhibitory activity. The reaction mixture in a total volume of $0.33 \mathrm{ml}$ contained $30 \mu \mathrm{g}$ of enzyme protein and $0.4 \mathrm{~A}_{260}$ units of primer. The enzyme was assayed as described in the text. Values in parentheses show the percent inhibition of the solubilized enzyme preparations (prior to chromatography) in which the enzyme is already associated with the endogenous primer 11,12 . One hundred percent activity in the purified enzyme corresponds to 120 picomoles AMP incorporated $/ \mathrm{hr}$. One hundred picomoles AMP incorporated corresponds to $1800 \mathrm{cpm}$.

Inhibition of poly(A) polymerase activity as a function of drug concentration. Figure 2 illustrates the effect of varying concentrations of $P R / 19$, $M / 88$ and $A F / A B D P$ that were used to inhibit the enzyme activity corresponding to $50 \mu \mathrm{g}$ enzyme protein. The degree of inhibition increased with increasing concentration of the drug. When used at concentrations up to $75 \mu \mathrm{g} / \mathrm{ml}, \mathrm{M} / 88, \mathrm{AF} / \mathrm{ABDP}$ and $\mathrm{PR} / 19$ inhibited poly(A) polymerase activity by $50 \%, 60 \%$ and $80 \%$, respectively.

Interaction of PR/19 with poly(A). polymerase. Although rifamycin has been clearly shown to bind to bacterial RNA polymerase, it was desirable to establish that at least one of the rifamycin derivatives used in the present studies interacted with the mitochondrial poly(A) polymerase molecule. The rifamycin derivative $P R / 19$, one of the most potent inhibitors of poly(A) polymerase, was used to demonstrate that the inhibitor affects the enzyme directly. The drug was added to the reaction mixture at a concentration sufficient to produce approximately $70 \%$ inhibition of poly(A) synthesis (Figure 3). If PR/19 inhibited poly(A) synthesis by binding to the primer, addition of more primer should restore the product formation. On the other hand, if the effect of the inhibitor is on the enzyme molecule, recovery of 


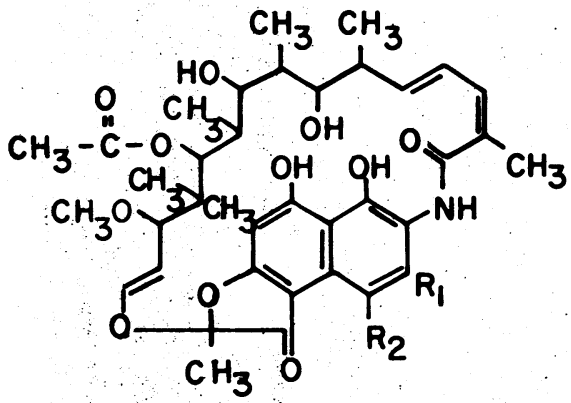

\section{STRUCTURE OF RIFAMYCIN NUCLEUS}

Figure 1. Structure of rifamycin nucleus.

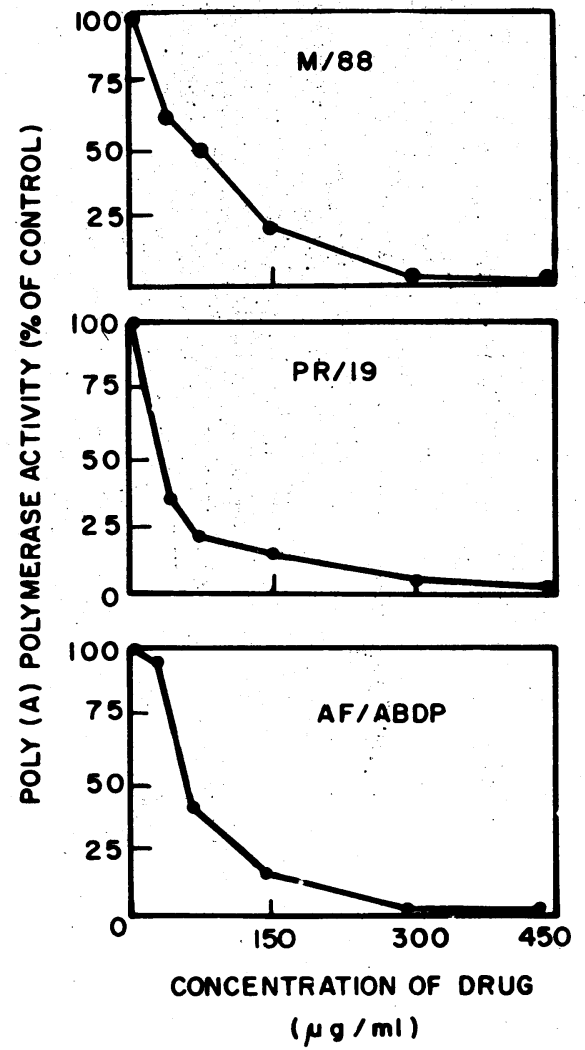

Figure 2. Inhibition of mitochondrial poly(A) polymerase activity at different doses of rifamycin derivatives.

Three rifamycin derivatives (M/88, PR/19, AF/ABDP) were used at different concentrations in a standard assay mixture containing $30 \mu \mathrm{g}$ of enzyme protein and $20 \mu \mathrm{g}$ of primer. The activity was expressed as percent of control. Activity in the control samples corresponds to 120 picomoles AMP Incorporated. 
poly(A) polymerase activity should be observed by addition of more enzyme. The latter possibility was proven to be the case, thus suggesting that $P R / 19$ and possibly other rifamycin derivatives interact with the enzyme, but not with the primer. The enzyme used in these experiments was totally dependent on the exogenous primer. PR/19 binds specifically to the enzyme protein since addition of bovine serum albumin $(1 \mathrm{mg} / \mathrm{ml})$ or heat-denatured cytoplasmic proteins did not alter the extent of inhibition by the drug. Also, the soluble enzyme preparation, which is only $2-10 \%$ as pure as the enzyme used in these studies, is totally inhibited by $300 \mu \mathrm{g} / \mathrm{ml}$ of the drug.

Effect of rifamycin derivatives on the addition of poly(A) to the primer already associated with enzyme. The enzyme in the solubilized extract from the mitochondria is firmly bound to the primer ${ }^{11}$ and consequently the activity of this enzyme preparation prior to purification ${ }^{12}$ is not dependent on an exogenous primer. AF/013, PR/19 and AF/ABDP inhibited the activity of this enzyme (Table 2, values in parentheses), thus suggesting that the inhibition is primarily at the elongation step. In order to further confirm the mode of action of the potent rifamycin derivatives on poly(A) polymerase, the purified enzyme freed of primer was pre-incubated with exogenous primer and substrate for 10 minutes and then the rifamycin derivatives (rifamycin SV, $M / 88, A F / A B D P$ and $P R / 19$ ) were added to the ongoing elongation reaction. The reaction was continued for an additional 50 minutes, during which period the enzyme reaction was linear. Control samples were incubated in the same manner with $10 \mu 1$ of dimethylformamide which itself had no inhibitory effect on the enzyme. As shown in Fig. 4, addition of rifamycin derivatives after pre-incubation for $10 \mathrm{~min}$ completely prevented further poly(A) synthesis. These experiments demonstrate again that the inhibitor does not interfere. with the complexing of the enzyme with primer, but rather inhibits the subsequent elongation of the primer with adenylic acid units.

Reversibility of the inhibition by increasing substrate concentration. In a series of experiments, the enzyme was pre-incubated with primer and a fixed ATP concentration for $3 \mathrm{~min}$ at which point $\mathrm{PR} / 19(300 \mu \mathrm{g} / \mathrm{ml} ; 350 \mu \mathrm{M})$ was added followed by further incubation for $1 \mathrm{~min}$. Subsequently the reaction was continued for an additional $20 \mathrm{~min}$ with (a) same ATP concentration $(120 \mu \mathrm{M})(\mathrm{b})$ additional $180 \mu \mathrm{M}$ ATP and (c) additional $360 \mu \mathrm{M}$ ATP. 


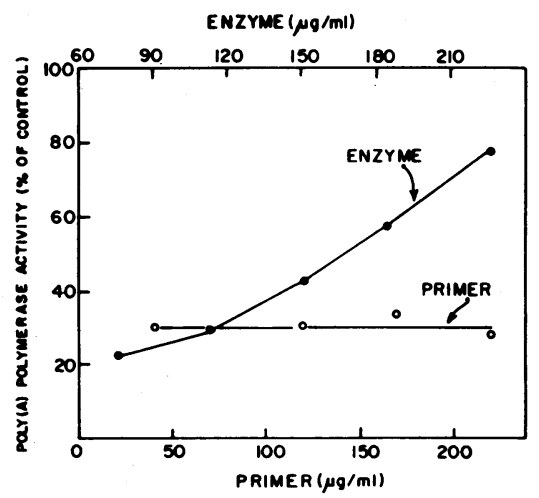

Figure 3. Effect of varying enzyme and primer concentrations on the inhibition of mitochondrial poly(A) polymerase activity by the rifamycin derivative PR/19.

The drug was used at a concentration $(50 \mu \mathrm{g} / \mathrm{ml})$ that produced approximately $70 \%$ inhibition of the enzyme activity. The reaction was initiated by addition of substrate. The restoration of the activity was examined (a) with a fixed amount (excess) of enzyme $(30 \mu \mathrm{g})$ and increasing amounts of endogenous primer $(0-0)$ and (b) with a fixed amount (excess) of endogenous primer $(60 \mu \mathrm{g})$ and increasing amounts of enzyme protein (- - $\bullet$ ). Even at the highest concentrations of enzyme or primer, the enzyme reaction was linear. The enzyme was assayed using purified endogenous primer as described in the text.

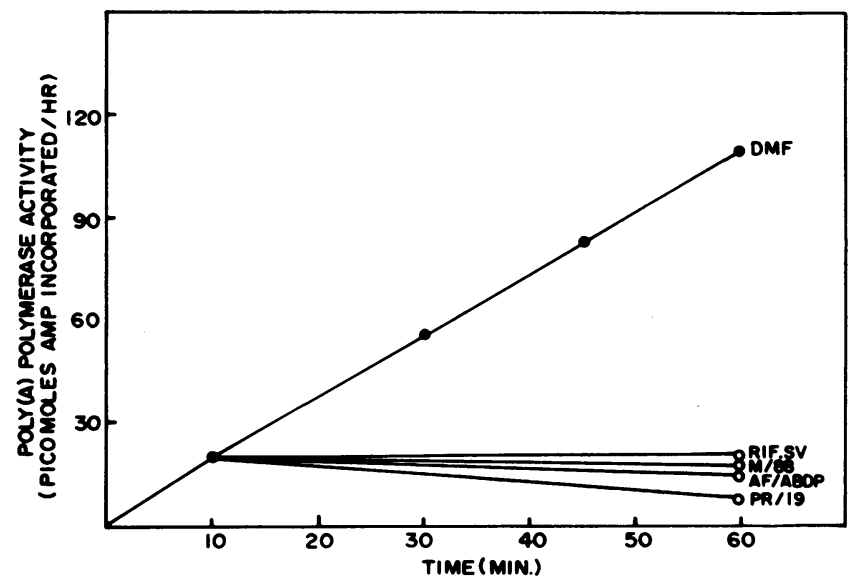

Figure 4. Effect of rifamycin derivatives on the enzyme reaction initiated with primer and substrate.

Rifamycin SV, M/88, AF/ABDP and PR/19 (each $300 \mu \mathrm{g} / \mathrm{ml}$ ) were added at $10 \mathrm{~min}$ after the enzyme reaction was started. Control samples contained dimethylformamide (DMF). The incubation was continued for a total of $60 \mathrm{~min}$, during which period the enzyme reaction was linear. The enzyme was assayed as described in the text. 


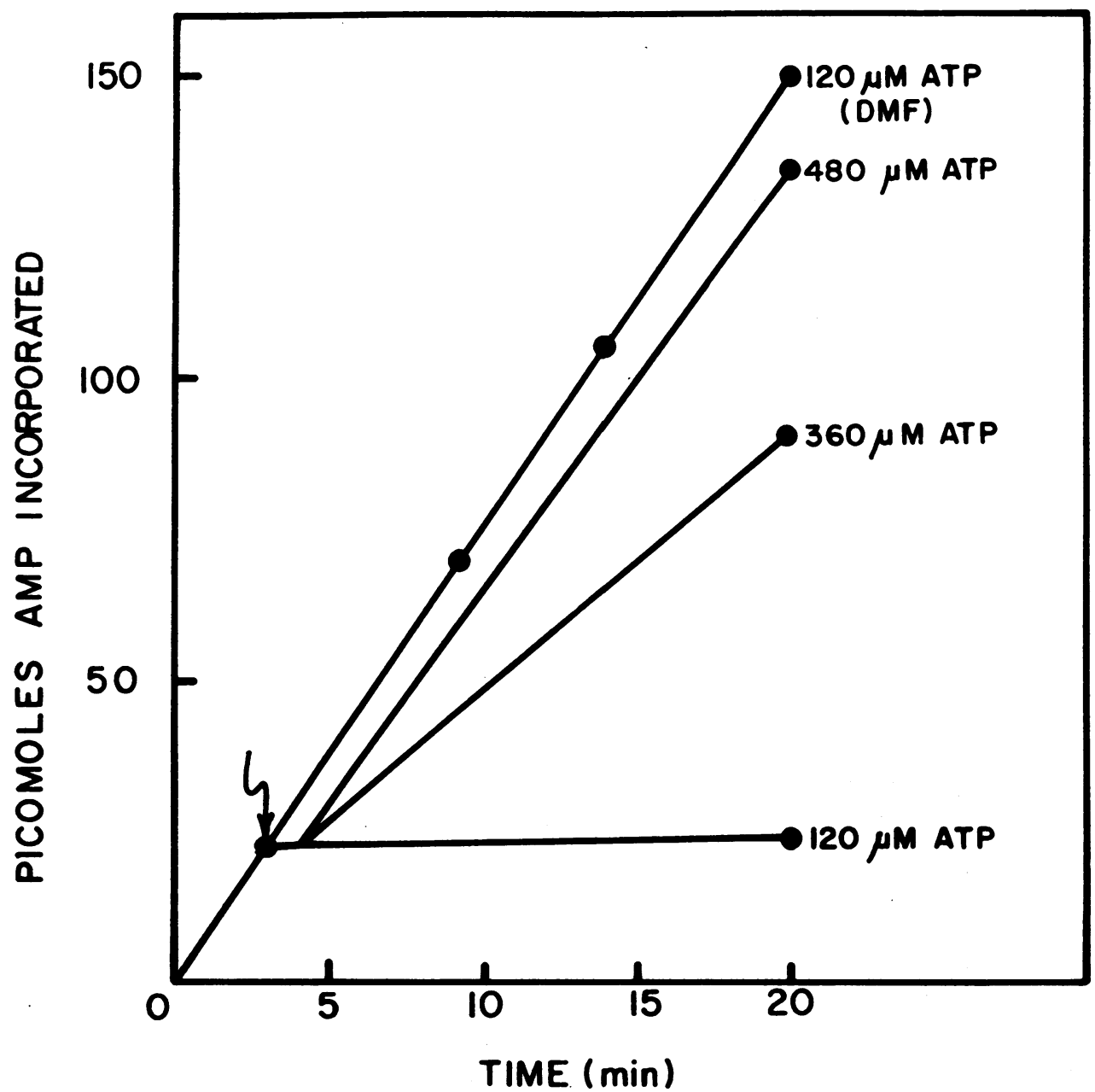

Figure 5. Reversal of inhibition of poly(A) polymerase by substrate. Enzyme $(50 \mu \mathrm{g})$ and primer $(20 \mu \mathrm{g})$ were incubated in the standard assay mixture containing $120 \mu \mathrm{M}$ ATP. After 3 min of $37^{\circ}, 10 \mu 1$ of DMF or PR/19 $(100 \mu \mathrm{g})$ was added as indicated by the arrow and allowed to equilibrate for $1 \mathrm{~min}$ at $37^{\circ}$. ATP concentration in the PR/19 samples was then Increased to $360 \mu \mathrm{M}$ or $480 \mu \mathrm{M}$ with $3_{\mathrm{H}-\mathrm{ATP}}$ of the same specific activity (1400 cpm/100 picomoles) as the contrrol. The reaction was continued for an additional $16 \mathrm{~min}$. All assays were performed in triplicate. The results are the average of three separate experiments. 
Ordinarily $120 \mu \mathrm{M}$ ATP was optimal for enzyme activity. When ATP concentrations were raised, labeled ATP was correspondingly increased to obtain comparable radioactivity incorporated into the product and enzyme activity was expressed as picomoles AMP incorporated. As shown in Figure 5, increasing the substrate concentrations resulted in recovery from inhibition by the drug. At the highest substrate concentration used, the activity had been restored almost to the control value.

\section{DISCUSSION}

The present studies demonstrate that in vitro some substituted rifamycin derivatives can inhibit poly(A) synthesis catalyzed by poly(A) polymerase from rat liver mitochondria. Since this reaction does not rely upon a template-dependent initiation, it is an ideal system to study the specific effect of compounds on the nucleotide chain elongation reaction. The extent of inhibition by $\mathrm{PR} / 19$ depends upon two factors a) the enzyme concentration and $b$ ) the substrate levels. Reversal of the inhibition by elevating the substrate level suggests that the drug interacts with the substrate binding site on the enzyme. While this manuscript was in preparation, we purified to homogeneity a poly(A) polymerase (molecular weight, 60,000 daltons) from mitochondria of hepatoma 3924A. At an enzyme concentration of $1 \mu \mathrm{M}, 180 \mu \mathrm{M}$ of AF/013 can completely inhibit product formation when the substrate concentration is $240 \mu \mathrm{M}$. Since the molar ratio of inhibitor to substrate is approximately 1 and the amount of drug necessary to Inhibit the reaction is directly related to the substrate concentration (manuscript in preparation), it seems reasonable to assume that only one molecule of inhibitor binds to the enzyme at any one time. The present studies indicate that the need for a high ratio of drug to enzyme may not be due to multiple binding of the drug to the enzyme, but the result of high substrate levels necessary for optimal enzyme activity.

\section{ACKNOWLEDGEMENTS}

The authors wish to thank Dr. G. Lancini (Gruppo Leptit Milan, Italy) for a generous gift of pure rifamycin derivatives, Ms. Judith Glaser and Rosemary Franzosa for excellent technical assistance. This work was supported by Public Health Service Research Grant No. CA 15733 from the National Cancer Institute. 


\section{REFERENCES}

1. Wehrli, W., Neusch, J., Knusel, F. and Staehlin, M. (1968) Biochim. Blophys. Acta, 157, 215-217.

2. diMauro, E., Snyder, L., Marino, P., Lamberti, A., Coppo, A. and Tocchini-Valentini, G.P. (1969) Nature, 222, 533-537.

3. Sippe1, A. and Hartman, G. (1968) Biochim. Biophys. Acta, 157, 218-219.

4. Umezawa, H., Mizuno, S., Yamazaki, H. and Nitta, K. (1968) J. Antibiot. Tokyo, A21, 236-237.

5. So, A.G. and Downey, K. (1970) Biochemistry, 9, 4788-4793.

6. Jacob, S.T., Sajdel, E.M. and Munro, H.N. (1968) Blochim. Biophys. Res. Commun. 32, 831-838.

7. Clark, R.J. (1971) New Eng1. J. Med., 284, 675.

8. Onishi, T. and Muramatsu, M. (1972) Biochem. J., 128, 1361-1364.

9. Meilhac, M. , Trysper, Z. and Chambon, P. (1972) Eur. J. Blochem. 28, 291-300.

10. Juhasz, P.P., Benecke, B.J. and Seifart, K.H. (1972) FEBS Lett. 27, 30-34.

11. Jacob, S.T. and Schindler, D.G. (1972a) Biochem. Biophys. Res. Commun. $48,126-134$.

12. Jacob, S.T., Rose, K.M. and Morris, H.P. (1974) Biochim. Biophys. Acta (in press).

13. Schnaitman, C. and Greenwalt, J.W. (1968) J. Cell. Biol. 38, 158-175.

14. Lowenstein, J., Schoite, H.R., and Wit-Peters, E.M. (1970) Biochim. Biophys. Acta, 223, 432-436.

15. Malkin, L.I. (1971) Biochemistry, 10, $4752-4756$. 